\title{
Putting reading in Northern Sotho on track in the early years: Changing resources, expectations and practices in a high poverty school
}

\author{
Elizabeth J. Pretorius \\ Department of Linguistics, University of South Africa \\ P.O. Box 392, UNISA 0003, Pretoria, South Africa \\ pretoej@unisa.ac.za \\ Matseleng M. Mokhwesana \\ Language Services, University of South Africa \\ P.O. Box 392, UNISA 0003, Pretoria, South Africa \\ mokhwmm@unisa.ac.za
}

\begin{abstract}
Large scale literacy assessments that have taken place during the past decade in South Africa indicate that our learners are struggling to read. Low reading competence occurs in all the home languages as well as in the medium of instruction, English. To date there has been very little research on reading in the African languages that can help to inform this situation. This article focuses on Grade 1 reading skills in Northern Sotho at a high poverty school where a reading intervention project was implemented over a four-year period. The aim of the project was to build a culture of reading at the school by creating conditions that are conducive for reading instruction and development. The purpose of this article is to examine the development of Grade 1 reading skills in Northern Sotho during this period and to reflect on possible changes that took place in the Grade 1 classrooms as a result of the intervention project. Although at the start of the project the reading levels at the school were extremely low, there has been a steady increase in various aspects of reading competence during the four years. It is argued that improvements in reading in the African languages are dependent on changes in instructional practices in classrooms. Such changes, in turn, will only take place if attention is paid to both resource building and capacity building in formal schooling contexts.
\end{abstract}

\section{Introduction}

In August 2006 the deputy director general of Education placed an open letter in prominent newspapers around the country exhorting principals and educators in primary schools to make reading a priority in their schools. This move was followed in February 2008 by the launch of the Foundations for Learning programme, an obligatory intervention that puts the teaching of literacy (and numeracy) on centre stage in primary schools during the first six years of schooling.

Two questions arise at this point: Firstly, why has the Department of Education deemed it necessary to make these moves? Surely the teaching of literacy is core business in primary schools anyway? And secondly, in what way is an article about reading in primary schools of relevance to an academic journal dealing with African languages?

Answers to these questions are nested in two main arguments on which this article is premised. Firstly, reading determines educational success and so it is important for educational systems to pay attention to reading development in their schools. Schools are the main state institutions tasked with the responsibility of developing literacy in successive generations of the populace. The effectiveness of an education system is judged by the literacy (and numeracy) levels that its learners achieve. The current low literacy levels in our schools (discussed below) necessitate closer attention to reading in our primary schools. 
Secondly, given the centrality of reading in scholastic achievement, it is not surprising that reading research occupies an important interdisciplinary niche in the academic world, straddling linguistic, neurolinguistic, cognitive, psychological, sociological, developmental and educational domains. Yet there is a virtual absence of research into reading in African languages and no academic journal on the continent that specializes in reading research. In this article we argue not only for the need for more African based research in this area but we also argue that the future of African languages in the $21^{\text {st }}$ century relies to a large extent on the extent to which speakers of these languages willingly and effectively read and write in these languages. Investing in the future of the African languages starts with the development of reading in the African home languages in primary schools.

In this article we look at the development of reading in Northern Sotho (henceforth N Sotho) in particular. We present longitudinal data from a typical disadvantaged township primary school where a reading intervention programme has been implemented to improve reading levels in the school. The aim of this study is to examine the effect the programme has had on the teachers and on the Grade 1 learners' reading abilities in N Sotho over a four year period and to reflect on the implications for literacy development in the African languages in primary schools as a whole.

\section{Reading instruction and development}

In order to situate the study within a broader context we first take a brief look at the larger South African schooling situation and thereafter we identify some of the factors that are important for establishing a sound foundation in reading.

\section{Literacy in South African schools}

During the past decade a series of large scale school literacy evaluations in Southern Africa have highlighted just how precarious South Africa's position is in the literacy stakes. For example, the Department of Education commissioned its first national systemic evaluations in 2001, when Grade 3 learners were tested for literacy (reading and writing) in their home language across all nine provinces. The results showed that Grade 3 learners achieved a national mean of $38 \%$ for reading and writing in their home language (Department of Education, 2003). In the Western Cape, for example, the province with the highest literacy levels, over 34,000 Grade 3 learners were assessed in literacy in either English, Afrikaans or Xhosa. An average of 39,5\% of the Grade 3 learners passed the literacy test on the Grade 3 level in the home language, only 62,7 \% of these learners met the Grade 2 literacy requirements, and 86,9\% met the Grade 1 literacy requirements. Research in the USA has found that how well a learner reads at the end of Grade 3 is a strong predictor of whether or not the learner will graduate from high school (Snow, Burns \& Griffin, 1998). If reading ability in Grade 3 is a predictor of completing high school, then the educational future looks bleak for the majority of our learners.

Indeed, further national systemic evaluations three years later showed that only $36 \%$ of Grade 6 learners passed the literacy test in the language of learning and teaching (LoLT). In all, 63\% of Grade 6 s fell into the 'Not Achieved' band, while only 28\% were functioning at or above grade level (Department of Education, 2005). Clearly literacy was not getting better as learners progressed up the schooling ladder.

More recently, South Africa participated in the Progress in International Reading Literacy Study (PIRLS) in 2006 and came last of the 40 participating countries. The PIRLS international scale average for Grade 5 was 500 points; the top countries (e.g. Russian Federation and Hong Kong) obtained average scores of 565 and 564 respectively while South Africa obtained the lowest average score of 302 (Mullis, Martin, Kennedy \& Foy, 2007). Not only did we come last, but we came badly last, with a long tail of underachievement: $78 \%$ of the Grade 5 learners did not even achieve the lowest reading benchmarks (Van Staden \& Howie, 2008).

It could be argued that the low reading levels in the Grade 6 systemic evaluations can be attributed to the fact that after Grade 3 the language of learning and teaching, for the majority of children, switches from an African lan- 
guage to English and that these learners are therefore not tested in their primary language. However, findings from biliteracy assessments do not necessarily indicate an advantage for reading in an African language in our current education system. Biliteracy studies with Grade 8 learners in Tswana and English (Matjila \& Pretorius, 2005) and Grade 6 and 7 learners in N Sotho and English (Pretorius \& Mampuru, 2007; Pretorius, 2007) showed that learners had generally low reading levels irrespective of the language in which reading was assessed. The findings from these small scale studies have recently been supported by the large scale PIRLS study, where over 16,000 South African Grade 4 learners were assessed in all 11 official languages. Grade 4 learners who did the reading tests in Afrikaans achieved the highest average score of 351, followed at an average of 346 points by learners who did the reading test in English (of whom 60\% were non-mother tongue speakers of English). Learners who had done Grades $1-3$ in an African language did the reading test in the African languages and obtained average scores below 250 points. Tswana Grade 4 readers did the best (average of 251 points), Ndebele readers were the lowest (176 points), while N Sotho readers obtained an average of just over 200 points (Van Staden \& Howie, 2008). The results from all these assessments clearly indicate that there is a literacy crisis in our schools. At whatever grade level and in whatever language they are tested, our children are struggling to read.

Our success in turning the literacy situation around in schools will depend to a large extent on our understanding of the factors that hinder or promote success in reading. Besides the language factor, there are many other contributory factors that immediately come to mind, including poverty, generally low adult literacy levels, the apartheid legacy of poor schooling for black children, poorly resourced schools, overcrowded classrooms and inadequate teacher training. Many of these are macro level factors which are unlikely to change in the foreseeable future and over which schools and teachers have little control. However, there are also many factors within the school and classroom context over which teachers do indeed have control. These relate to the time and effort spent providing opportunities for learners to practise reading and building positive attitudes to books and reading. The kind of reading ability that learners develop in school is a direct reflection of what is (or is not) happening in the classroom. The reading scholar McGuiness bluntly asserts that 'reading is a learned skill. Ignorance or incompetence in teaching this skill can produce a large number of children with severe reading problems' $(2005: 217)$.

For answers as to how best to help learners become skilled and effective readers we need to turn to scientific evidence on how factors in home, school and classroom contexts impact directly or indirectly on language, cognitive development and reading achievement. We first look briefly at the kind of knowledge and skills that help children learn to read successfully and then we look at some school and classroom factors that impact on reading development.

\section{What do children need to know in order to learn to read?}

Reading does not just 'happen' the way that language acquisition happens. Reading needs to be taught and developed and it can take many years of regular exposure to a wide variety of texts for learners to become fast, accurate and comprehending readers. Reading comprises two main components, viz. decoding and comprehension. Decoding refers to the code-based processes involved in translating the written symbols on the page into identifiable chunks of language, while comprehension refers to the processes that assign meaning to the text as a whole. Decoding and comprehension occur simultaneously and interactively during reading. While comprehension is not possible without decoding, decoding is necessary but not sufficient for comprehension.

There are many things that children need to learn in order to learn to read successfully in their first year of formal schooling (e.g. Snow \& Dickinson, 1991; Hiebert, 1993; Gee, 2001). Some of these relate more directly to the decoding aspects and others to the comprehension aspects. For some children learning to read happens relatively easily and seamlessly, for others this literacy breakthrough can become a slow and effortful process (e.g. Wells, 1985; Hiebert, 1993; Spear-Swerling, 2004).

Oral language development: Although all children have acquired the basics of their primary language within the first 5-6 years of their lives, they do not all come to school with the same command of their language. Children's 
oral language development when they start school has been found to predict how easily they learn to read and write in Grade 1. The assumption is that children with a better command of language become more efficient readers because they have access to phonological, semantic and morphosyntactic information that helps them decode the written symbols on the page (Snow et al., 1998). Children need practice in reading sentences in extended little texts so that they can learn to rapidly process the morphological and syntactic relationships that hold between words in a sentence (Wolf \& Katzir-Cohen, 2001).

Vocabulary: Strongly linked to oral language is vocabulary development. Children come to school with a range of different receptive and expressive vocabularies. The size of children's vocabularies has regularly been found to be related to socio-economic status (SES): the higher the SES, the larger the child's vocabulary (e.g. White, Graves \& Slater, 1990; Hart \& Risley, 1995; Stipek \& Ryan, 1997). Vocabulary knowledge has consistently been linked to successful reading (e.g. National Reading Panel, 2000), especially in reading comprehension. Vocabulary knowledge at the start of school has also been found to predict academic performance in the first three years of schooling (Hart \& Risley, 1995).

Phonological awareness and sound-letter relationships: Phonological awareness refers to the understanding that spoken language consists of sequences of sounds. Children may not be aware that the flow of speech can be broken down into smaller sound units, and that these sounds (phonemes) are represented by letters of the alphabet. The ability to grasp the alphabetical principle depends on the ability to hear sounds in words and to match up these sounds to letters or groups of letters. Research has consistently shown that a lack of phonemic awareness is one of the most important reasons why many children initially have difficulty learning to read. Phonemic awareness is important for learning to read, as well as for spelling and writing (e.g. MacDonald \& Cornwall, 1995; Gottardo, Stanovich \& Siegal, 1996).

If children grasp the alphabetic principle then this enables them to learn how letters are used to form the building blocks of words (e.g. Ehri \& Chun, 1996; Spear-Swirling, 2004). Unlike English, African language orthographies are phonetically transparent. Letter-sound relationships are usually practised through basic consonant-vowel syllable structures used to build up words. Hence the famous syllable routines that African children typically recite from the chalkboard: $b a, b e, b i, b o, b u ; m a, m e, m i, m o, m u$. However, African languages are also tone languages, so while syllables within words might be structurally similar, their vowels may differ in tone. Syllables per se have no meaning and need to be decoded in the context of words and sentences.

Word recognition and lexical access: The ability to recognize words rapidly and accurately is vitally important in fluent reading. Automaticity in word recognition refers to the processing of written language with little effort and attention (Geva \& Zadeh, 2006:32). This frees up the memory to engage comprehension processes.

Lexical access refers to the ability to retrieve a word's meaning from memory during reading (Just \& Carpenter, 1987; Stanovich, 1993). However, the notion of a 'word' is more complex in the agglutinating African languages with their richly inflected morphosyntactic constructions. Thus, morphosyntactic units that would be considered as separate words in English are often written together in an African language. Unlike English with its abundance of high frequency single syllable words, high frequency words in the African languages that children in the foundation phases are expected to read often comprise three or four syllables and carry not only lexical but also morphological content, especially in the conjunctive orthography of the Nguni languages.

The implications of agglutinating languages for early reading instruction are obvious: children need to develop sound decoding skills in the early grades in order to chunk up the complex morphosyntactic code underlying the orthography. During the foundation phase there should be a brisk and steady development of lower level decoding processes involving orthographic, phonological, lexical, morphological and syntactic skills. It is important 
for children to increase their reading repertoire of orthographic units that are easily accessed from memory and to carry out decoding operations with speed (McDonald Connor, Morrison \& Katch, 2004).

A lot of instructional time and effort in the early school years go into teaching children to decode. There is good reason for this: 'children who haven't mastered these basic reading skills read with difficulty, read more slowly, make more errors and don't really understand what they're reading' (Geva \& Zadeh, 2006:32). The developmental trajectory for decoding skill should happen as quickly as possible in Grade 1 and practised through regular exposure to texts and plenty of opportunities to read and write. However, attention also needs to be given simultaneously to developing comprehension skills in children.

Comprehension: Reading is essentially about comprehension so although the decoding aspects are necessary for reading, they are not sufficient. Children may become efficient decoders but may still not really understand what they are reading (Daneman, 1991; Pretorius, 2002; Cutting \& Scarborough, 2006). Decoding and comprehension skills should happen simultaneously and interactively during reading. While children learn to decode the written language, they should also be building up comprehension skills to enable them to grasp the overall meaning of the strings of words and sentences that they read. It is thus important to develop decoding and comprehension simultaneously and not sequentially (National Reading Panel, 2000).

Children only develop comprehension skills if they are given opportunities to practise decoding skills in a meaningful context. In other words, they need to be exposed to extended texts such as short little stories. Storybook reading, where teachers read and then discuss stories with children, has consistently been found to develop comprehension skills in young children. Such adult mediated interactions confer numerous cognitive and linguistic advantages on children. For example, children exposed to storybook reading tend to have larger vocabularies, wider background knowledge, and better language and conceptual development than their peers who have not been exposed to books or storybook reading (e.g. Wells, 1986; Elley, 1991; Elley \& Cutting, 2001; Feitelson, Goldstein, Iraqi \& Share, 1993; Vivas, 1996; Neuman, 1999). In their study Jordan, Snow and Porche (2000) found that children who had opportunities to engage in book-mediated activities made significantly greater gains in vocabulary, story comprehension and sequencing in story-telling than children not exposed to such activities. Ntuli and Pretorius (2005) found that Zulu preschool children exposed to regular storybook reading in Zulu had better story comprehension skills and they used longer and more complex sentences when retelling stories than did Grade 1 children who were a year older but who had not been exposed to storybook reading.

Not only does storybook reading develop language and reading competence; through storybook reading children also develop discourse competence and become acquainted with literacy conventions. For example, they learn how pictures support text, how sentences are organized at paragraph and text level, they acquire a schema for how written stories are sequenced and structured (e.g. setting, characters, and how the protagonist overcomes a problem) (e.g. Holmes, 1987; Vivas, 1996; Neuman, 1999; Jordan et al., 2000). Although children may not be able to articulate this text-based knowledge, they can demonstrate this knowledge if asked to retell a story (Ntuli \& Pretorius, 2005). Through storybook reading children also learn to enjoy reading, engage with texts and infer human intentions and moral themes, which form the basis for critical text evaluation (e.g. Feitelson et al., 1993). In sum, storybook reading is strongly linked not only to comprehension development but also to school performance in general.

Literate behaviours and practices: Literacy is not just about learning to decode and comprehend written symbols on a page; it is also a form of human behaviour that is socially constructed and valued in specific ways. Research has shown that home factors affect children's reading development. Children learn literate behaviours from the adults in their lives. For example, in the preschool years they learn that the printed word is meaningful if they see their parents or other adults around them regularly engaging in literate activities (reading newspapers, magazines or books, making lists, writing notes, letters or reports, working on computers, going to libraries or book shops) and if there are print based resources in the home (books, magazines, newspapers, etc.). Many of these literate 
activities are related to socio-economic status (SES) factors, for instance children from middle class homes tend to be immersed in more literacy activities and have greater access to print material from an early age than their poorer peers. In particular, storybook reading in the home has consistently been found to be a strong predictor of later success in school (e.g. Hiebert, 1993; Jordan et al., 2000).

Having looked at some of the knowledge, skills and attitudes that children bring with them when they start school and that consequently affect their reading development, we now briefly look at school based factors that influence early reading development.

\section{What makes for effective reading classrooms in the early years?}

The question of how reading is best taught has led to many heated debates. One way of side-stepping the theoretical minefield of these reading debates is to look at reading outcomes. There have been several studies that have compared schools that produce good readers with schools that have weak readers in order to identify factors and conditions associated with successful reading. Research indicates that effective literacy classrooms are characterized by a combination of school, teacher and classroom factors (e.g. National Reading Panel, 2000; Taylor, Pearson, Clark \& Walpole, 2000; Department of Education, 2005; Sailors, Hoffman \& Mathee, 2007; Van Staden \& Howie, 2008).

School based factors associated with successful literacy development include strong school-parent links, regular assessment of learners' reading to monitor progress and inform classroom instructional decisions, early reading interventions to help struggling readers, and good communication and collaboration amongst teachers within and across grades on issues related to reading and learner progress.

Teacher based factors included time given to small-group reading instruction, time spent on reading activities, combining phonics instruction with word identification strategies, engaging learners in authentic reading tasks and allowing for independent classroom reading, asking higher-level questions, and engaging learners in writing tasks in response to reading activities. In all the effective schools, reading was a priority at both school and classroom level, and books were visible and accessible. In the Taylor et al. (2000) study, effective schools averaged 134 minutes a day on reading activities, excluding time spent reading storybooks to the children. In the PIRLS study Grade 4 learners were found to receive 6 hours a week of explicit reading instruction on average, internationally; in South Africa, $72 \%$ of Grade 4 teachers spend less than 3 hours a week on reading (Van Staden \& Howie, 2008).

Classroom based factors: In all the studies, effective literacy classrooms also had the characteristics associated with effective teaching in general (e.g. good classroom management, providing safe and stimulating learning environments). Other features related to literacy instruction in particular, viz. a balanced approach combining skills development (e.g. phonics) with authentic reading experiences such as storybook reading, integrating reading and writing, devoting considerable time to reading tasks, and cultivating positive attitudes to reading. Furthermore, effective schools also assess reading regularly and help children with reading problems (e.g. Pressley, Rankin \& Yokoi, 1996; National Reading Panel, 2000; Taylor et al., 2000).

In addition, access to books is a basic requirement for reading development, yet often absent in high poverty schools. In the International Studies in Educational Achievement in 32 countries, differences in reading ability were consistently associated with availability of books: 'the general message is that books are essential, no matter how rich or poor a nation is' (Ross \& Postlethwaite, 1994:147).

Having sketched the broader context in which reading develops, we now turn to the South African context. If our children are reading poorly in the African languages, then we need to examine more carefully what is happening in the classrooms where African languages are being taught. The study reported in this article hopes to make a contribution in this regard. 


\section{Research context and questions}

In 2005 a reading project, 'Reading is FUNdamental', was initiated at a high poverty primary school in Gauteng. The project aims to help the school optimize conditions that promote the development of sound reading so that the school can develop a culture of reading which in turn will improve the overall language and academic development of the learners. A multi-level approach is adopted that emphasizes resource and capacity building and involves the participation of the learners, teachers and parents.

In this article we briefly outline the intervention programme at the school and examine the effects that it is having on Grade 1 learners in the home language N Sotho, over a period of four years. The main research questions that we address in this article are:

- Has performance in N Sotho literacy development in Grade 1 changed since the inception of the reading intervention?

- In what way have the N Sotho classrooms changed during the four years?

- In what way have the teachers practised N Sotho literacy instruction during this period?

\section{Methodology}

\section{The school context}

The school, Batho Pele Primary School ${ }^{1}$, is one of the poorer performing primary schools in the township. The school has just over 600 learners and a staff of 16 teachers and 2 administrative personnel. The school is a nonfee paying Quintile 1 school. It serves a socio-economically disadvantaged community and has a feeding scheme, where 400 children ranging from Grades $\mathrm{R}-7$ are fed once a day.

$\mathrm{N}$ Sotho is the language of learning and teaching (LoLT) from Grade R - Grade 3, after which English becomes the LoLT. N Sotho becomes a subject of instruction from Grades 4-7. Although many children come from homes in which a variety of African languages are spoken, about $70-80 \%$ of the learners come from primarily N Sotho speaking homes and about $60 \%$ of the teaching staff have N Sotho as their primary language.

\section{Prior to intervention}

On initial visits to the school prior to and in the early stages of the intervention it was clear that reading did not play a significant role at the school. None of the classrooms were print rich environments, homework was not common, and reading homework was non-existent. Reading tests administered to learners at the start of the project pointed to extremely low reading levels in the school (the Grade 7 average for reading comprehension in English was $29,5 \%$ and for N Sotho $30 \%$ ).

In the Foundation Phase, reading was primarily taught from the chalkboard, where lists of letters, words and sentences were written up and the children were drilled in identifying and saying them aloud in unison. Writing was done in worksheets pasted into exercise books. Particularly striking was the absence of storybook reading in the classes. The teachers did not read stories to the class, and there were no little texts or books for the children to read individually or in small groups to practise reading in meaningful contexts. There was a N Sotho reader for Grade 1s (comprising 392 words) but copies of the book were stored away in classroom cupboards because it was felt that the book was too difficult for the learners. Thus during their first year of formal schooling the children had no opportunity to practise reading a connected text in $\mathrm{N}$ Sotho of less than 400 words. This is in stark contrast to effective schools where good Grade 1 readers read up to 1,200 words a week (Stanovich, West, Cunningham, Cipielewski \& Siddiqui, 1996).

All the teachers in the Foundation Phase were receptive to new ideas about how reading in N Sotho could be best developed. The two Grade 1 teachers had taught Grade 3s previously but they said that the children who came into their classes in Grade 3 couldn't read and they felt that they wanted to do something about this situation. They had 
thus asked the principal if they could be allowed to teach Grade 1s instead. The year in which the project began was the same year in which these teachers had started teaching Grade 1s, so they were receptive to new ideas about early reading instruction. After the third year the one Grade 1 teacher left as she did not have a permanent post at the school, and a former Grade 2 teacher took up Grade 1 teaching.

\section{The reading intervention programme}

The project adopted a two pronged approach to reading, viz. resource building and capacity building.

\section{Resource building: school library}

An important component of the project was to build up print resources in the school. Before the project there was a small room designated the library but it was actually used as a storeroom cum office and there was no lending system. The first step was to clean out this room, install a computer, printer, scanner and library software programme. A young man from the community was appointed and trained as school librarian. New and age appropriate storybooks were purchased in N Sotho and English with project funding and books were also donated from a more privileged private 'twinning' school. After eight months the library was fully functional and all staff and learners in the school issued with library cards.

A library committee has since been formed, a library policy drawn up, and every year about 10 volunteer Grade 6 and 7 learners serve as library monitors and help the librarian. They are also expected to serve as reading role models. The librarian is at the school every day and the library is open during school hours and until mid- afternoon. Learners take out books during break times and after school. The library now has a regular stream of users on a daily basis.

The school library now boasts a collection of just under 5,000 books ${ }^{2}$. Of these only 170 titles are N Sotho books, and these are mainly storybooks for children under the age of ten. Despite an explicit policy that promotes reading in the home language and the purchase of N Sotho for the school library, there is not a wide variety of books available in N Sotho; there are very few non-fiction books in N Sotho, and also very few N Sotho books for teenagers.

\section{Resource building: classrooms}

Besides the school library, the project has also encouraged teachers to create print rich environments and build up resources in their classrooms. Initially the only books that were visible in the Grade 1 classrooms were workbooks, so the teachers were encouraged to develop reading corners in their classrooms and were given a set of 120 easy storybooks in N Sotho for each classroom (the READ Sunshine series with 20 titles x 6 copies per title). The teachers were also encouraged to display the learners' drawings and writing, to make alphabet and number charts, $\mathrm{N}$ Sotho flashcards and labels for objects in the classroom to help children identify common words.

\section{Capacity building}

Literacy resources have no value if not used properly. In high poverty areas where adult literacy levels are low and where reading for leisure is uncommon, teachers - and parents - need to be shown what to do with books. The intervention thus also focuses on developing the instructional capacity of the teachers and the supportive capacity of the parents.

Before the start of the project the teachers were asked to fill in a questionnaire that tapped their perceptions of and attitudes to reading and their home and school reading practices. At the start of the project, none of the teachers was a member of a community library and $69 \%$ indicated that they had 10 or fewer books in the home. Responses such as these suggested that reading did not play a significant role in the daily lives of these professionals.

Building teacher capacity: Workshops were held fortnightly with the teachers after school with a focus specifically on reading. The aim was to increase teachers' understanding of the reading process and its development, familiar- 
ize them with reading strategies, draw attention to the OBE assessment standards for reading and different ways of assessing reading at the various grade levels, and integrating the library into their classroom practices. Arrangements are also made for teachers to take turns, by prior appointment, to spend a morning observing good reading practice in a grade equivalent classroom in a highly effective school where reading is a priority.

The importance of storybook reading, especially in the Foundation Phase, was emphasized, and teachers were shown effective ways of reading storybooks to their class so as to engage the children's attention and optimize learning. The importance of developing reading skills in $\mathrm{N}$ Sotho from an early age was constantly emphasized.

Building parent capacity: The Family Literacy component: The teachers often commented that many parents regarded the school as being responsible for their children's schooling, and consequently did not get involved in their children's school activities. Parents with low literacy levels may also be disinclined to help their children in areas in which they perceive themselves to lack skills. In order to involve parents more actively in the literacy development of their children, a family literacy component is included in the project.

A set of Family Literacy workshops were held for Foundation Phase parents on Sunday mornings at the school (the only day available for parents to attend school related activities), and refreshments served afterwards. The principal and teachers at the relevant grade levels attended and facilitated the workshops. The aim of these workshops is to draw parents' attention to the importance of reading and to encourage them to read to their children and/or to listen to their children reading. A 20-minute video in N Sotho on how to read storybooks to children is shown and one of the teachers also reads a story to demonstrate to the parents how children can enjoy and be engaged in storybook reading. Other topics are also covered, such as taking an interest in children's school activities, making time and space available in the home for homework, encouraging membership of the local community library, monitoring what and how much TV children watch, and ensuring that children go to bed at appropriate hours. After each workshop, handouts are given in both English and N Sotho, summarizing the main points of the workshop.

To help in teacher development the project sponsored the enrolment of two teachers for a certificate course in Parent Involvement through Unisa each year. In all, six teachers completed the course (one gained a distinction), and one Grade 1 teacher also completed a certificate course in teaching children with learning problems.

\section{Literacy assessments}

In order to monitor the literacy accomplishments of the learners over time, a quasi-experimental, pre- and posttest design is used to assess the reading skills of Grade 1 (N Sotho) and Grade 6 and 7 (N Sotho and English) learners every year. These assessments also serve to establish benchmarks for literacy development at entry and exit levels in the school. In this article we focus specifically on the Grade 1 literacy assessments and it is to these methodological concerns that we now turn.

\section{Participants}

Assessing literacy at Grade 1 level is time consuming as children should ideally be tested individually, on a oneto-one basis. Each year 10 children were selected from the Grade 1 classes on the basis of stratified sampling: 3 struggling, 3 strong and 4 average learners were selected. The Grade 1 learners ranged in age from 5 to 8 years.

\section{Assessment}

A battery of tests was used to assess the Grade 1 learners. Two N Sotho lecturers from the Department of African Languages, Unisa, were coached in early literacy assessment and assessed the Grade 1 children twice a year over a four-year period. The assessments comprised the following components: 
- Letter and sound identification: Each child is asked to name and sound 10 letters of the alphabet in N Sotho. Plastic letters (in lower case) are spread out on the desk for the child to look at and move around. The number of letters correctly sounded are noted on an observation sheet and tallied for each child.

- Phonemic awareness: There were two listening subtasks. In the first the child is asked to say whether pairs of words said aloud are the same or not (e.g. dula - pula versus dira - bala). In the second task the child hears a word, repeats it and then is asked to delete a sound or syllable (e.g. say bolela; now say bolela without bo -> lela). Examples are practised before assessment starts.

- Story recall: Retelling a story that had been read to all the children at the beginning of the assessment session. The main events in the story are identified beforehand and the main events in each learner's recall compared to this template. Because this is not a memory test, the child is handed the storybook and asked to recall the events from the book.

- Book behaviour: The learner is handed the storybook upside down and back to front, and the researcher observes the learner's familiarity with storybooks (holding the book correctly, turning pages in the appropriate direction, identifying a page number and a word on a page, etc.).

- Vocabulary: The Renfrew test is used to test the learners' vocabulary. The test comprises 50 line drawn picture items, starting with familiar every day items (e.g. cup, spoon) to more unfamiliar items (e.g. aerial, igloo). To make the test more culturally sensitive to the South African context, six of the items were replaced with more familiar items (e.g. a scarecrow was replaced by a picture of a bird's nest with eggs in it, a lighthouse was replaced by a picture of a rainbow). The test has been standardized on socio-economically diverse groups of children in Britain, Australia and South Africa.

- Word recognition: The children are given a list of 30 high frequency words in N Sotho to read. The aim of this word recognition test is to assess automatic recognition of words that should be familiar to children at this level.

- Letter: The learners are asked to write a letter to the teacher to say that Thabo, a doll used in the group storybook reading session, is sick and was not coming to school that day. Even if they cannot yet write, they are encouraged to pretend to write a letter. The letter is a way to indirectly assess each child's concept of letters, words and discourse level features (e.g. date, greeting, content, salutation). Writing is analysed in terms of the following developmental stages:

- the precommunicative stage (the child produces pictures or logographs, wavy lines, ball and stick letter or random letter like shapes);

- the emergent letters stage (with random ordering of letter like shapes, which later approximate letters more clearly);

- the phonetic stage (where a few letters represent words without spaces and then later with spaces);

- the transitional phase (vowels and consonants occur in syllables and the child's own spelling is interspersed with standard spelling forms);

- the standard orthography phase.

\section{Assessment procedures}

The two assessors started the assessment sessions with a group storybook reading. To contextualize and authenticate the story recall task that was to follow, they introduced a large black doll, Thabo, to the children before the story reading. Thabo sat on the assessor's lap during the story reading. After the storybook reading, the children were engaged with the drawing to put them at their ease, and later with the letter-writing task. The learners were called up one by one and assessed individually on the tasks, with short breaks in between to minimize fatigue.

Assessments occurred twice a year: first in April (the pretests) and then again in November (the posttests). Due to the relatively long period between the assessments it was decided that there would be few memory effects, so the same tests were used in the pre- and posttests. The data were captured and analysed on SPSS (Statistical Package for the Social Sciences). 


\section{Results}

We turn to the first research question: Has performance in $N$ Sotho literacy development in Grade 1 changed?

We unpack this question into two parts, viz. decoding and comprehension skills. Firstly, we look at those aspects of literacy development that reflect decoding skills, such as letter knowledge, the ability to detect similar/different sounds in words, the ability to segment sounds in words (phonological awareness), and the ability to recognize common N Sotho words. Table 1 reflects the pre- and posttest performance of the Grade 1 learners with regard to decoding skills over the four-year period.

Table 1: Comparison of Grade 1 decoding skills in N Sotho

Pre- and posttests 2005-2006

\begin{tabular}{|c|c|c|c|c|c|c|c|c|}
\hline & \multicolumn{2}{|c|}{ Letter knowledge } & \multicolumn{2}{|c|}{ Auditory discrimination* } & \multicolumn{2}{|c|}{ Phonological awareness* } & \multicolumn{2}{|c|}{ Word recognition } \\
\hline & & Post & Pre & Post & Pre & Post & Pre & Post \\
\hline 2005 & 38 & 73 & & & & & 0 & 38 \\
\hline 2006 & 27 & 91 & & & & & 8 & 69 \\
\hline 2007 & 57 & 92 & 50 & 52 & 29.1 & 43.3 & 8 & 57 \\
\hline 2008 & 90 & 91 & 65 & 76 & 44.1 & 68.3 & 30.6 & 70 \\
\hline
\end{tabular}

* These two assessment measures were only introduced in 2007 in order to get a fuller picture of the development of decoding skills.

As can be seen from the table, there has been a steady increase in all skill areas over the four-year period. In the first year of the project even the posttest results in the first year show mediocre levels of performance - for example, very few learners could read words in N Sotho at the end of the year and achieved an average of $38 \%$ only. Four years later nearly all the learners tested could recognize high frequency N Sotho words fairly easily and rapidly, and the group average rose to $70 \%$. One also notices that each year the learners generally performed higher at the pretest level than they did the previous year, which suggests that the teachers now have higher expectations of what the learners can and should achieve and are teaching to higher standards of literacy performance, and they are achieving this earlier in the year. For example, during the first two years of the project the childrens' pretest knowledge of letters was below $40 \%$ at pretest time but by 2008 the group achieved near mastery (90\%) of letters by pretest time. Their performance on the phonological awareness tests also improved, suggesting that the teachers are giving more attention to basic phonics. Phonological awareness develops if children are explicitly taught sound-letter relationships and can recognize sounds and their sequence in words. These are all components that contribute to the development of decoding skill.

A significant correlation (Spearman's rho $\mathrm{r}=.67, \mathrm{p}<0.001$ ) obtained between phonological awareness and word recognition. In other words, there was a strong relationship between children's ability to identify and manipulate sounds in a word and their performance on the word recognition task.

This steady increase in decoding is also reflected in the children's letter writing. In the first year of the project many children didn't understand what they were asked to do and struggled with the task. Several children wrote letters in any sequence (the emergent letters stage as in Figure 1 [a]) and even when words were discernible, there were seldom gaps between them (the early phonetic phase as in Figure $1[\mathrm{~b}]$ ), suggesting that the children did not yet have a clear concept of individual words. 
Figure 1: Posttest writing in 2005

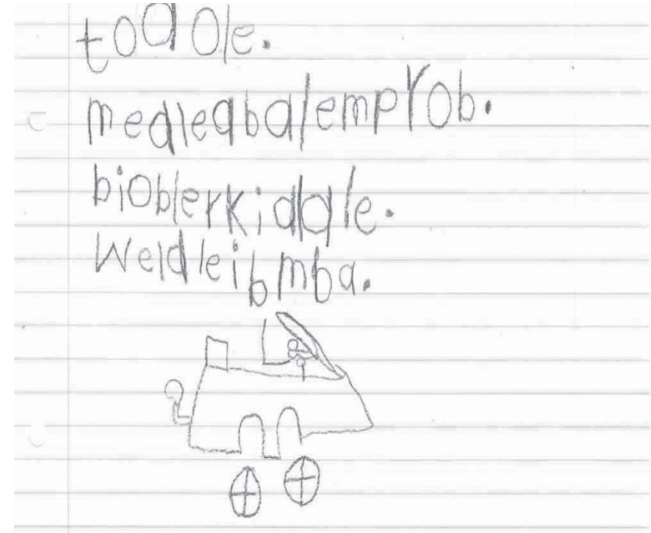

[a]

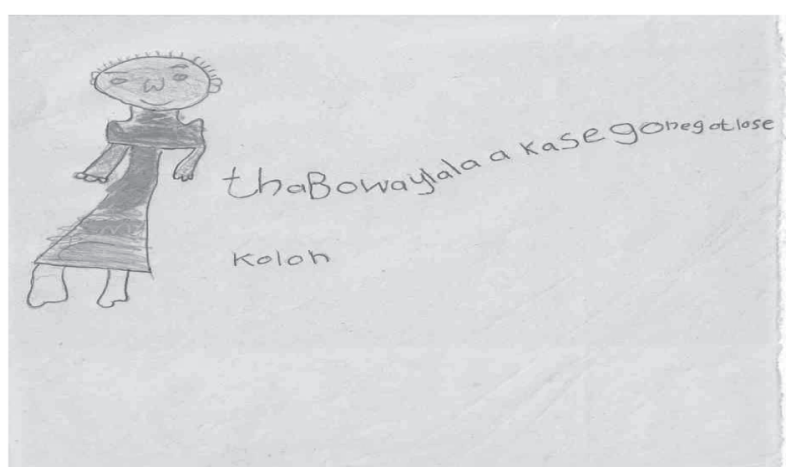

[b]

Four years later many of the children wrote their letters with confidence and were clearly familiar with this kind of literacy activity. Even though their writing does not yet reflect standard disjunctive orthography in all respects (as in Figure 2 [a] and [b]) they are familiar with the salutation and greeting conventions of this genre of writing.

Figure 2: Posttest writing in 2008

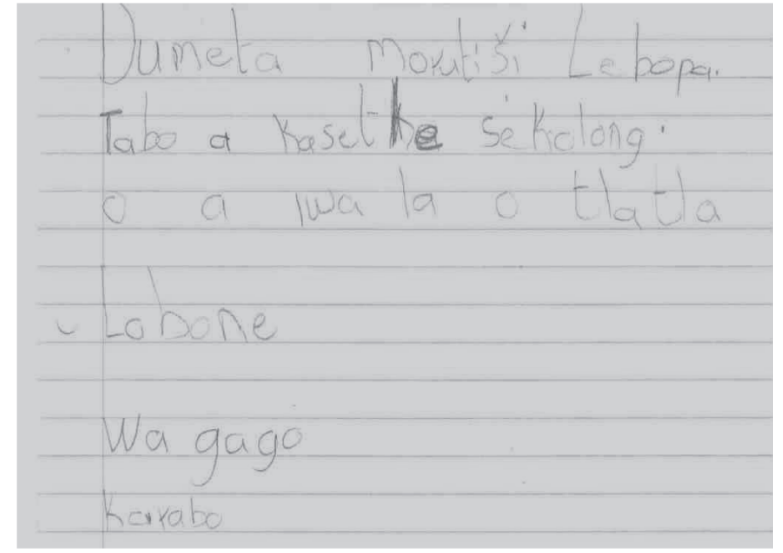

[a]

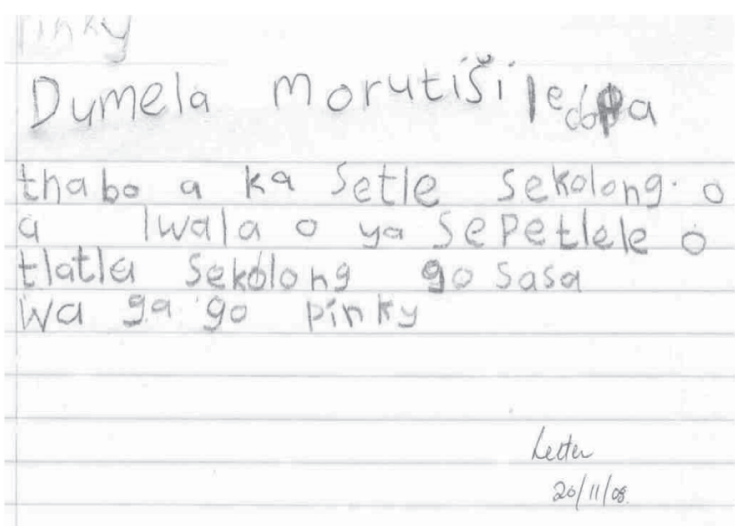

[b]

We now turn to those aspects of reading that relate more generally to comprehension abilities. These include measures of story recall (children retelling a story that was read to them earlier), vocabulary knowledge and book behaviour. The results are reflected in Table 2 below.

Table 2: Comparison of Grade 1 comprehension and general literacy skills Pre- and posttests 2005-2006

\begin{tabular}{|l|ll|ll|ll|}
\hline & \multicolumn{3}{|l|}{ Story recall } & \multicolumn{2}{l|}{ Vocabulary } & \multicolumn{2}{l|}{$\begin{array}{l}\text { Book behaviour } \\
\text { Pre }\end{array}$} \\
& Pre & Post & Pre Post & Post \\
\hline $\mathbf{2 0 0 5}$ & 48 & 24 & \multicolumn{2}{|c|}{-} & 68.5 & 76 \\
\hline $\mathbf{2 0 0 6}$ & 34.3 & 67.5 & $41.6 \quad 53.6$ & 83 & 85 \\
\hline $\mathbf{2 0 0 7}$ & 46.2 & 60 & 47 & 52 & 74 & 74.6 \\
\hline $\mathbf{2 0 0 8}$ & 50 & 80 & 41.4 & 52 & 75.3 & 89.2 \\
\hline
\end{tabular}


Despite some variability, here too we see an increase in ability from pre- to posttest. The children are clearly becoming more familiar with storybook reading routines such as listening to stories and retelling the story afterwards. The pretest scores tend to show an increase during the four-year period, indicating earlier acquisition of this ability in the Grade 1 classroom. The measure of book behaviour assesses how familiar children are with books (e.g. holding them the right way up, turning pages correctly, identifying what on the page 'tells the story', their ability to concentrate on the task at hand, etc.). This is an aspect of literacy development which grew quickly in the children and which indicates that they are familiar with literacy activities.

However, an area that clearly needs more attention is that of vocabulary development. Although there is a slight increase in vocabulary knowledge from pretest to posttest each year, there is clearly room for greater growth. The ages of the Grade 1 children ranged from 6-8 years; according to the norm tables for this vocabulary test, these children show vocabulary growth of 3-4 year-old children. This is a test of vocabulary development, not conceptual development. What is interesting about their responses on the test is that while the children could sometimes correctly describe an object, e.g. an aerial may be described as selo sa TV ('a thing for the TV'), they often had not yet acquired a specific label for the object. In other words, they may have acquired the relevant concept but it had not yet been lexicalized in their N Sotho vocabulary. Attention needs to be given to increasing the children's knowledge of N Sotho words during their Foundation Phase years.

In sum, the results from the literacy assessments on the whole show a steady increase in both decoding and comprehension aspects of reading development.

The second research question is: In what way have the classrooms changed in the four year period? To answer this question we present some observations of the classrooms and the literacy activities from a more qualitative point of view.

Observations of the Grade 1 teachers and learners were made on a regular basis by the project co-ordinator. The lecturer from the N Sotho Department (the second author of this article) also did some classroom observations. The researchers observed the teachers and children, talked to the teachers, took photographs of the interior of the classrooms and teacher-child interactions at least twice a year, and made field notes. The children were used to the project team and so their presence in the classrooms did not disrupt normal classroom proceedings.

Although at the start of the project the Foundation Phase classrooms contained more print materials than the other classrooms in the schools, since the inception of the project the Foundation Phase teachers have made an effort to enhance their classrooms and provide greater print-rich environments for their learners. The teachers are developing more of their own teaching and learning resources and their classrooms offer a wide array of visually stimulating material by way of books, posters, flashcards, etc., as can be seen from the photographs in Figure 3. Learners' own written and art work is now regularly pinned up; some posters have been changed to relate more closely to what knowledge and skills are being handled at the time and the teachers are developing their own charts and flash cards in N Sotho.

The teachers also have a bookcase in their classrooms where a small collection of storybooks in N Sotho is kept. Children can go to the bookcase when their work is done and take a book to read. They also have a box of books from the library for additional classroom reading which is renewed fortnightly. Reading activities in N Sotho certainly play a greater role in daily classroom activities than in the past. 
Figure 3: Creating stimulating print-rich environments in Grade 1 classrooms ${ }^{3}$
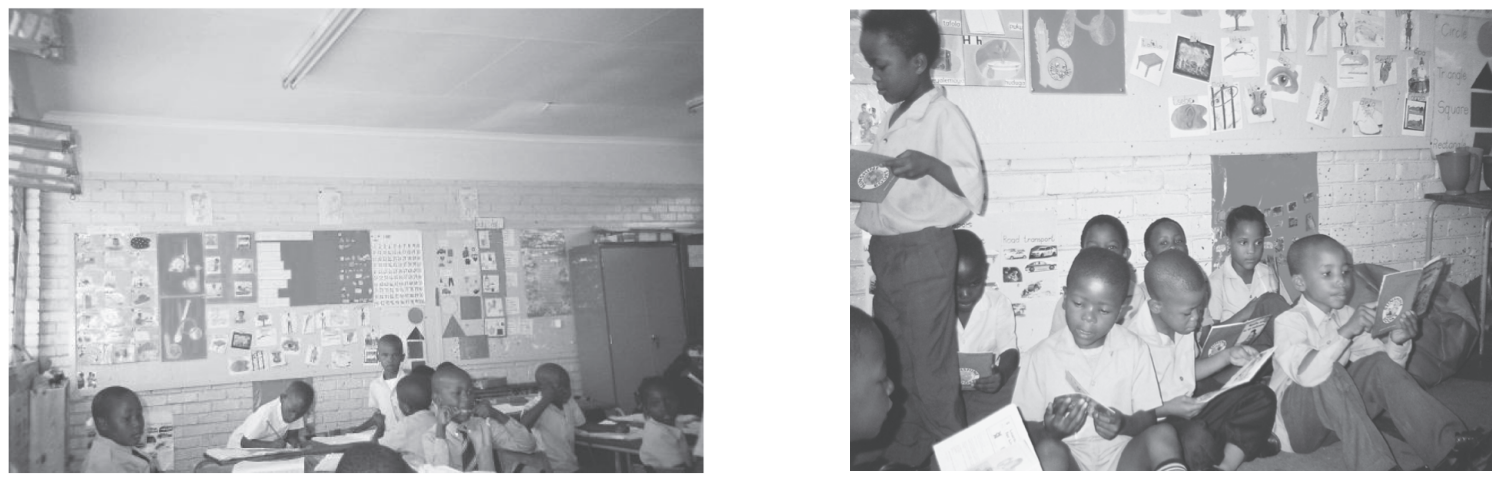

Although labels for objects in the classroom are put around the walls, and charts of days of the week, months of the year and so on also appear, standard forms are not always used, e.g. sehlare instead of mohlare for 'tree', tsuonyana instead of tsuanyana or tswiana for 'chicken' and ngoako instead of ngwako for 'hut'. Sometimes phrases are also written conjunctively (Mmele waka; goja) instead of disjunctively (Mmele wa ka; go ja). On the whole, though, the classrooms now certainly provide the learners with a stimulating, print rich context in which $\mathrm{N}$ Sotho literacy can be developed.

The third research question focuses on the teachers themselves, viz.: In what way have the Grade 1 teachers changed?

Similar to most Grade 1 classrooms, a phonics approach forms the basis for reading instruction. The teaching of the letters/sounds of the alphabet and of syllables and sight words is still done from the chalkboard, with children chanting appropriate responses in unison. N Sotho flashcards made by the teachers are now used more often. Activities in workbooks help to reinforce the phonics principles. However, since the start of the project storybook reading in N Sotho has become a regular - and much loved - activity in the Grade 1 classrooms. The Grade 1 teachers have become very good storybook readers and they read with enthusiasm and dramatic flair. Storybook reading is also used to introduce lessons and themes, to develop vocabulary and to familiarize children with the language of written $\mathrm{N}$ Sotho. Teachers also make use of paired reading (pairing a strong reader with a weaker reader) and peer reading (reading with partners at same level) to increase opportunities for reading practice. A more balanced approach to reading is now being adopted, with phonics activities explicitly taught but at the same time the use of storybook reading sessions means that these reading phonic principles are embedded and practised in a more meaningful context than was previously the case.

Changes in knowledge can also bring about changes in expectations. This was tellingly demonstrated when, at the start of the project, one of the Grade 1 teachers expressed the hope that by the end of the year some of her learners 'would be able to read some words'. When it was suggested that many of the Grade 1s should already be reading short simple texts much earlier in the year, she expressed polite disbelief. After spending a morning at a high functioning school where she observed Grade 1 learners read storybooks in the second term, she was motivated to work towards similar levels of literacy achievement. By raising her expectations of what her learners could achieve, she worked to that goal. Posttest assessments of her Grade 1 learners testify that several of her learners can now read aloud quite fluently from little storybooks. The HOD of the Foundation Phase remarked that this was not something that they would have expected from Grade 1s in previous years. However, this should be viewed relative to the school context. If the teachers were pleased that half the children were actually reading short little texts by the end of the year, this suggests that prior to the intervention they expected less than this. This small change in itself is a necessary step to shifting teacher expectations and hence learner performance over time. 
The Grade 1 teachers commented that they have a stronger sense of a shared vision of what they need to do with their children and they work closely together in planning lessons and sharing ideas. They now also have a greater awareness of the importance of storybook reading and the way in which it facilitates literacy development. The children also take home little books once a week and read to their parents or ask their parents to read the book to them. Even though this kind of reading homework should take place on a daily basis during the week, the fact that it takes place at all - albeit once a week - is a step in the right direction.

The enrolment of the teachers in the certificate course in parent-school relationships as well as the workshops that the project has facilitated have helped to broaden the Grade 1 teachers' frame of reference and instilled a greater sense of pride and professionalism in their teaching. The teachers have adopted a more proactive approach to the parents. They try to involve parents and encourage them to read at home to their children and listen to their children read. They now write letters to parents whose children are struggling to read and make suggestions to parents as to how to help their children at home and they also invite parents to come and see them at school to discuss their children's progress.

The teachers have become more familiar with the genre of children's literature, especially for younger readers. However, they have also become aware of the limited quantity of their book collections and the needs of their learners, and they frequently express the desire for more books. Given the funding constraints of the project as well as the limited number of storybooks in N Sotho, the supply of a wide variety of storybooks in the mother tongue remains a problem.

\section{Discussion}

We need to recognize that reading is a learned skill; it is also a socially constructed form of behaviour. How well children read in school, how much they read and whether or not they enjoy reading are a direct reflection of what is happening in the schools and classrooms that these children inhabit.

What can we learn about early reading in N Sotho from this four-year intervention project? Batho Pele was a poor school before the intervention project, and it remains a poor school. It serves children who come mainly from informal settlements, where many parents have low literacy levels and high levels of unemployment. Its buildings are tatty, there are broken windows and door handles, the cement floor in many of the classrooms is chipped and uneven, and classroom furniture is old and often in disrepair. None of these macro level factors have changed. Yet our findings indicate that some changes are indeed happening inside the classrooms: on nearly all components of the battery of tests used to assess reading development at the school, the Grade 1 learners are performing better. Four years ago, hardly any of the children could read easy, high frequency words in N Sotho; now several of them can read short little stories in N Sotho. Admittedly, there are still some children who are struggling to read and the overall mastery levels in both decoding and comprehension can still be improved. On the whole, however, the children are reading better, they are reading earlier, they are reading more and they enjoy reading.

It could be argued that the sample size is too small for generalizations to be made. The small sample is certainly a limitation of the study. However, by testing 10 children in detail twice a year over a 4-year period we have managed to build up a nuanced and informed view of how different N Sotho reading skills are being developed in these classrooms. The data has been further triangulated by classroom observations and ongoing conversations with the teachers. These findings provide a feasible basis for asserting that changes are happening in these classrooms.

If there are changes in Grade 1 reading outcomes, this implies that some changes in instructional practices are taking place. What factors may have helped bring about these changes? We argue that changes in instructional practices do not happen easily or quickly for they are mediated by teachers' knowledge, beliefs and practices, as well as the support given to teachers. 
Teacher knowledge: The workshops organized by the project have helped to make the teachers more knowledgeable about reading. They have become more aware of the importance of reading in schooling, the need to spend time teaching it, to provide learners with opportunities to practise reading in meaningful ways through storybooks, the need to identify children with reading problems and to help them, and the need to constantly encourage and motivate learners to read. The teachers were constantly reminded to promote and encourage reading in the African languages and this may have helped to validate reading in the N Sotho classrooms. There is now a discourse about reading at the school amongst teachers, between teachers and learners, and between teachers and some of the parents. Becoming more knowledgeable about reading has helped the Grade 1 teachers become more focussed and purposeful in their teaching of reading.

Beliefs and practices: Some of the qualitative evidence points to changes happening in teachers' beliefs about reading. For example, the almost total absence of storybook reading in the classrooms before the intervention suggests that teachers did not perceive this to be a serious or useful learning tool. The fact that it has now become a regular and popular activity suggests a revision of this belief. As noted previously, one Grade 1 teacher reported that she now uses storybooks not just for reading but to introduce themes that are covered in the syllabus generally. Her experience of the children learning more easily and in meaningful ways though storybook readings in N Sotho has brought about a change in classroom practice. The fact that the teachers have also become good storybook readers themselves has made it easier for them to integrate this practice into their regular classroom activities, and must surely contribute to their self-esteem and self-confidence as teachers. Oral storytelling is a rich African tradition and transforming the oral storytelling mode into a print-based literacy activity may be a natural and enjoyable step for these teachers to make.

Becoming more knowledgeable about reading has also raised teachers' expectations of what learners can and should do in Grade 1. The achievement bar was very low at the start of the project; now the teachers expect more of their learners, they expect it to happen more quickly, and they are changing their practices accordingly.

Support for teachers: Changes in literacy practices in the African language classrooms will not easily happen unless teachers - especially those in poor schools - are given support. Support can come in different forms, for example, material, professional and psychological.

Only reading can develop reading, and reading can only develop if children have texts to read. Children and teachers need easy access to books, and teachers need resources such as storybooks and readers in their classrooms. At a practical level, they also need cupboards or bookshelves for storing and managing these resources. At a material level, the project has enabled changes in N Sotho reading through the building up of print-based resources at the school. Four years ago very few books were visible in the school and there was no school library. Now the learners and staff have access to 5,000 books in the library. Admittedly, with only $170 \mathrm{~N}$ Sotho titles in the library (there are more than $170 \mathrm{~N}$ Sotho books in the library as there are two or three copies of some titles), the children have access to far fewer books in N Sotho than in English. The genre of children's literature in the African languages is one that needs to be further developed and nurtured.

However, resources on their own are not effective unless teachers are shown how to use them and are persuaded that the resources are indeed useful and beneficial. Teachers need to be given professional support by way of capacity building. As discussed above, providing opportunities for teachers to become more knowledgeable about reading, helped them change some of their classrooms practices. The fact that the teachers at the school were initially not knowledgeable about reading raises questions about teacher training, especially in the Foundation Phase. In order to put literacy in the African languages on centre stage, reading development needs to be a core component of teacher training, especially in the primary school phase. 
Teachers who are under pressure to change their classroom practices also need emotional support. Teachers in high poverty schools have additional challenges because they lack the support structures, resources and parental input that teachers at more privileged schools have access to. In this study the project co-ordinator visited the school on a weekly basis, did regular observations and gave teachers personal and confidential feedback on their lessons, project members worked with the teachers, took an interest in what they were doing and got to know them quite well during the 4-year period. The friendly relations between the teachers and project members helped to create a nonthreatening space within which teachers could try out new activities in their classrooms. The need for teachers to be encouraged, affirmed and given regular feedback is an often neglected component of intervention programmes that attempt to bring about instructional changes.

The recent initiatives by the Department of Education, referred to at the start of the article to put literacy on centre stage in primary schools, indicates a recognition that literacy has been neglected. The success of these literacy initiatives will depend on many factors. The findings from this study indicate that future reforms of the way in which reading is taught, developed and valued in the African languages, will need to be tied to resource building as well as capacity building. The one has no value without the other.

\section{Implications}

Early literacy instruction in the African languages often happens in the context of high poverty schools. In fact, it has been estimated that about $80 \%$ of South African school children are underperforming and come from disadvantaged schools (Fleisch, 2008). It is mainly in these schools where early literacy is taught in an African language (Grades 1-3) and where an African language is taught as a subject from Grade 4-12. If children get off to a bad start in reading in their home language then they may never get out of that developmental trajectory and their reading skills will fall more and more behind as they move up the educational ladder. However, poverty need not be destiny. This longitudinal small scale study provides robust evidence that putting reading on track in $\mathrm{N}$ Sotho in a highly disadvantaged school is possible, provided teachers know how to do it and have the resources to do so. This obviously has research and pedagogical implications.

It is ironic that many African Language departments at universities around the country have been downscaled or face closure at a point in South Africa's history when our educational system is in crisis because of low literacy levels, especially in the African languages. The virtual absence of research into literacy in general and reading in particular in the African languages should provide a powerful incentive for African language specialists, linguists and educationists (and university management) to apply their expertise to this underresearched domain.

- Teachers who teach through the medium of an African language in the Foundation Phase or who teach an African language as a subject in the higher grades should have a sound knowledge of the languages that they teach. Studying an African language up to at least third year level should be compulsory for such teachers. Teaching literacy skills such as reading and writing requires more advanced, academic knowledge of a language than basic interpersonal communicative competence in a language.

- Courses on the sociocultural and linguistic nature of literacy, specifically reading development in the African languages, could also be offered in African Language departments. This will also open up research incentives and opportunities in reading in the African languages.

- Phonological awareness has been shown to be an important component of early reading success. It can also be used to identify children at risk of reading so that early intervention can be provided. The role of phonological processing during reading and the design of phonological awareness tests in the African languages are areas that merit research.

- Because of their agglutinating nature, African languages have rich and complex morphologies. Yet very little is known about the role of morphological processing in the development of fluent decoding, especially in conjunctive orthographies. African linguists could make important contributions in this regard.

- Given that children's oral language development is a strong predictor of early success at school, more research is needed to describe and understand the different home language competencies that African children from varied 
backgrounds bring with them to school. Vocabulary development in the African languages in particular is an underresearched yet vitally important domain. It can be linked to corpus linguistic research and the frequency levels and functions of linguistic items used in oral and written discourses. Research worldwide consistently shows a strong relationship between vocabulary knowledge and academic success, yet there are no reliable and valid vocabulary measures in the African languages that researchers can use in Southern Africa.

- The effect that storybook reading in the African languages has on children's comprehension, conceptual and vocabulary development, and general background knowledge are areas awaiting further research.

- Anecdotal evidence in our project work suggests that Sesotho sa Pretoria rather than Sesotho sa Leboa is persistently and widely used by teachers and learners alike in the classrooms. Has a diglossic situation arisen with regard to the spoken and written forms of the African languages? How does this affect the development of reading and writing in these languages? In their research Feitelson et al. (1993) found that Palestinian children who spoke non-standard Arabic dialects became bidialectal when they were exposed to storybooks in standard Arabic. Similar research would be of relevance in the South African context.

- The genre of children's literature in the African languages is a slowly expanding domain of interest. Teenage literature in the African languages is almost non-existent, yet it has the potential to open up a whole new domain of literacy activity and interest. The argument is often put forward that publishers are reluctant to publish books in the African languages because there is not a market for them. Instead of assuming that a market must first exist, ways should rather be explored of creating a new market. If primary schools in the townships started buying collections of storybooks in the African languages for classroom use and made storybook reading an integral classroom activity, this would help to create a new market for children's literature in the African languages.

\section{Conclusion}

Our information-driven society of the $21^{\text {st }}$ century places a high demand on the use of effective and efficient literacy skills in many different educational, economic, commercial and social contexts. In order to put children, especially poor children, on a successful learning trajectory from the start of their schooling, reading instruction needs to be done well in whatever language it is offered. Developing readers in the African languages starts in Grade 1. For these children to be successful they need access to books, they need opportunities to read, they need to be motivated to read and they need knowledgeable teachers to help them learn to read. The findings from this study indicate that when these factors are in place then even in high poverty contexts children can learn to read well and to love reading in their home language. This is surely a sound investment for the future of the African languages.

\section{Acknowledgements}

The authors would like to acknowledge the central role that the Foundation Phase teachers at the school - specifically the Grade 1 teachers - played during the intervention period. We salute the dedication, patience and hard work of Dikeledi, Rosinah and Hilda, and their belief that they can make a difference in less than ideal circumstances.

Thanks are also due to the supportive and hospitable principal and staff at the school, and to the unswerving commitment of the project team members: Sally Currin, Nicoline Wessels and Debbie Mampuru.

Finally, we thank the anonymous reviewers for their useful comments on the article.

Funding from the NRF and the DG Murray Trust made this research project possible. The opinions expressed here are not necessarily those of the funders.

\section{Notes}

1. Not the real name of the school.

2. In 2008 the library was judged the best school library serving a disadvantaged community in Gauteng.

3. At the start of the project the school granted permission for photographs to be taken on the school premises for project and research purposes during the course of the intervention period. 


\section{References}

Cutting, L.E. \& Scarborough, H.S. 2006. Prediction of reading comprehension: Relative contributions of word recognition, language proficiency and other cognitive skills can depend on how comprehension is measured. Scientific Studies of Reading 10(3):277-299.

Daneman, M. 1991. Individual differences in reading skill, in Handbook of reading research, Volume II, edited by R. Barr, M.A. Kamil, P. Mosenthal \& P.D. Pearson. London: Longman:512-538.

Department of Education. 2003. National report on systemic evaluation: Mainstream Foundation Phase. Pretoria: Department of Education.

Department of Education. 2005. Systemic Evaluation Report: Intermediate Phase Grade 6. Pretoria: Department of Education.

Ehri, L.C. \& Chun, C. 1996. How alphabetic knowledge/phonemic knowledge facilitates text processing in emergent readers, in Literacy and education, edited by J. Shimron. Cresskill, NJ.: Hampton Press:69-93.

Elley, W.B. 1991. Acquiring literacy in a second language: The effect of book-based programmes. Language Learning 41:375-411.

Elley, W.B. \& Cutting, B. 2001. The 'Sunshine in South Africa' literacy project. International Journal of Educational Research 35:127-135.

Feitelson, D., Goldstein, Z., Iraqi, J. \& Share, D.L. 1993. Effects of listening to story on aspects of literacy acquisition in a diglossic situation. Reading Research Quarterly 28:71-79.

Fleisch, B. 2008. Primary education in crisis. Cape Town: Juta.

Gee, J.P. 2001. Reading as situated language: A sociocognitive perspective. Journal of Adolescent and Adult Literacy 44:714-725.

Geva, E. \& Zadeh, Z.Y. 2006. Reading efficiency in native English-speaking and English-as-a-second-language children: The role of oral proficiency and underlying cognitive-linguistic processes. Scientific Studies of Reading 10(1):31-57.

Gottardo, A., Stanovich, K.E. \& Siegal, L.S. 1996. The relationship between phonological sensitivity, syntactic processing and verbal working memory in reading performance of third grade children. Journal of Experimental Child Psychology 63:563-582.

Hart, B. \& Risley, T.R. 1995. Meaningful differences. Baltimore, MD: Paul H. Brookes.

Hiebert, E.H. 1993. Young children's literacy experiences in home and school, in Reading across the life span, edited by S.R. Yussen \& M.C. Smith. New York: Springer-Verlag:33-55.

Holmes, B.C. 1987. Children's inferences with print and pictures. Journal of Educational Psychology 79:14-18.

Jordan, G.E., Snow, C.E. \& Porche, M.V.2000. Project EASE: The effect of a family literacy project on kindergarten students' early literacy skills. Reading Research Quarterly 35:524-546.

Just, M.A. \& Carpenter, P.A. 1987. The psychology of reading and language comprehension. Boston: Allyn \& Bacon.

MacDonald, G.W. \& Cornwall, A. 1995. The relationship between phonological awareness and reading and spelling achievement eleven years later. Journal of Learning Difficulties 28:523-527.

Matjila, D.S. \& Pretorius, E.J. 2005. Bilingual and biliterate? An exploratory study of Grade 8 reading skills in Setswana and English. Per Linguam 20:1-21.

McDonald Connor, C., Morrison, F.J. \& Katch, L.E. 2004. Beyond the reading wars: Exploring the effect of childinstruction interactions on growth in early reading. Scientific Studies of Reading 8(4):305-336.

McGuiness, D. 2005. Language development and learning to read. Cambridge, Mass.: MIT Press.

Mullis, I.V.S., Martin, M.O., Kennedy, A.M. \& Foy, P. 2007. IEA’s progress in international reading literacy study in primary school in 40m countries. Chestnut Hill, MA: TIMSS \& PIRLS International Study Center, Boston College. Available: http://pirls2006/intel_rpt.html. Accessed on 2007/02/05.

National Reading Panel. 2000. Teaching children to read: An evidence-based assessment of the scientific literature on reading and its implications for reading instruction. Washington, DC: US Government Printing Office.

Neuman, S.B. 1999. Books make a difference: A study of access to literacy. Reading Research Quarterly 34:286-311. 
Ntuli, D. \& Pretorius, E.J. 2005. Laying foundations for academic language competence: The effects of storybook reading on Zulu language, literacy and discourse development. Southern African Linguistics and Applied Language Studies 23(2):91-109.

Pressley, M., Rankin, J. \& Yokoi, L. 1996. A survey of the instructional practices of outstanding primary-level literacy teachers. Elementary School Journal 96:363-384.

Pretorius, E.J. 2002. Reading ability and academic performance in South Africa: Are we fiddling while Rome is burning? Language Matters 33:179-208.

Pretorius, E.J. 2007. Looking into the seeds of time: Developing academic literacy in high poverty schools. Ensovoort 11(2):105-125.

Pretorius, E.J. \& Mampuru, D.M. 2007. Playing football without a ball: Language, reading and academic performance in a high poverty school. Journal of Reading Research 30(1):38-58.

Ross, K.N.\& Postlethwaite, T.N. 1994. Differences among countries in school resources and achievement, in The IEA study of reading literacy: Achievement and instruction in thirty-two school systems, edited by W.B. Elley. Oxford: Pergamon:123-147.

Sailors, M., Hoffman, J.V. \& Mathee, B. 2007. South African schools that promote literacy learning with students from low-income communities. Reading Research Quarterly 42(3):364-387.

Snow, C.E. \& Dickinson, D.K. 1991. Skills that aren't basic in a new conception of literacy, in Literate systems and individual lives, edited by E.M. Jennings \& A.C. Purves. New York: State University of New York Press:178-218.

Snow, C.E., Burns, M.S. \& Griffin, P. 1998. Preventing reading difficulties in young children. Washington, DC: National Academy Press.

Spear-Swerling, L. 2004. A road map for understanding reading disability and other reading problems: Origins, prevention and intervention, in Theoretical models and processes of reading ( $5^{\text {th }}$ ed.), edited by R.B. Ruddell \& N.J. Unrau. Newark, De.: International Reading Association:517-573.

Stanovich, K.E. 1993. The language code: Issues in word recognition, in Reading across the life span, edited by S.R. Yussen \& M.C. Smith. New York: Springer-Verlag:111-135.

Stanovich, K.E., West, R.F., Cunningham, A.E., Cipielewski, J. \& Siddiqui, S. 1996. The role of inadequate print exposure as a determinant of reading comprehension problems, in Reading comprehension difficulties: Processes and intervention, edited by C. Cornoldi \& J. Oakhill. Mahwah, NJ.: Lawrence Erlbaum:15-32.

Stipek, D.J. \& Ryan, R.H. 1997. Economically disadvantaged preschoolers: ready to learn but further to go. Developmental Psychology 33:711-723.

Taylor, B.M., Pearson, P.D., Clark, K. \& Walpole, S. 2000. Effective schools and accomplished teachers: Lessons about primary-grade reading instruction in low-income schools. The Elementary School Journal 101:121165.

Van Staden, S. \& Howie, S.J. 2008. South African teacher profiles and emerging teacher factors: The picture painted by PIRLS 2006. Paper presented at TLEP Conference, 4-5 September 2008, Boksburg.

Vivas, E. 1996. Effects of story reading on language. Language Learning 46:89-216.

Wells, G. 1985. Preschool literacy-related activities and success in school, in Literacy, language and learning, edited by D.R. Olson, N. Torrance \& A. Hildyard. Cambridge: Cambridge University Press:229-255.

Wells, G. 1986. The meaning makers: Children learning language and using language to learn. London: Hodder $\&$ Stoughton.

White, T., Graves, M. \& Slater, W. 1990. Growth of reading vocabulary in diverse elementary schools: decoding and word meaning. Journal of Educational Psychology 82:281-289.

Wolf, M. \& Katzir-Cohen, T. 2001. Reading fluency and its intervention. Scientific Studies of Reading 5:211-238. 